\title{
Poor and dissatisfied? Income poverty, poverty transitions and life satisfaction in Chile
}

\author{
Emma Samman and María Emma Santos
}

\begin{abstract}
Chile is an interesting country in which to study the relationship between poverty and subjective wellbeing, having experienced a remarkable fall in poverty over the past two decades. This paper explores how poverty status and transitions in and out of poverty contributed to life satisfaction in the late 2000s. Using new data for 2006 and 2009, we find that poor people were more dissatisfied with life than the non-poor and that income gains did not appreciably affect the satisfaction of the poor while they remained below the poverty line. People who were not poor in either period exhibited higher satisfaction than those who were poor in both periods, while those who escaped poverty between 2006 and 2009 exhibited higher satisfaction than those who remained poor. In addition, people who fell into poverty in 2009 were no more or no less satisfied with their lives than those who were poor in both periods. The evidence suggests poor people may not have adapted to their circumstances, in contrast to much literature exploring income dynamics and life satisfaction, and also that people's recent experiences appear to affect their perceptions more than more distant ones.
\end{abstract}

\section{Introduction}

This paper addresses the relationship between poverty and subjective wellbeing in a developing country setting. Chile makes a very interesting country in which to study this issue, having experienced very high levels of economic growth since the late 1980s. Despite high inequality, this growth has translated into dramatic reductions in income poverty (CEPAL, 2000; Larrañaga, 2009), interrupted only by the 2008 global financial crisis. Indeed, Chile is the first country in Latin America to halve extreme poverty. ${ }^{1}$ Accordingly, the country provides a perspective not only on the effects of poverty but on persisting poverty amid rapid societal change.

The literature on income and subjective wellbeing suggests two possible hypotheses. The first is that income poverty is associated with lower subjective wellbeing. A great deal of work focusing on the form and strength of the relationship between income and happiness, or life satisfaction, ${ }^{2}$ concludes that average country income matters, at least to a certain threshold level (pegged somewhere between US $\$ 10,000$ and US\$20,000). Above that threshold, the well-known Easterlin paradox holds: additional increases in income do not raise life satisfaction (Easterlin, 1974) - though some recent work maintains that income does in fact continue to matter when different econometric methods are used (Deaton, 2008; Stevenson and Wolfers, 2008). ${ }^{3}$ It follows that being in poverty may exercise a particularly negative effect 
on life satisfaction. The existing evidence suggests that subjective wellbeing is - on average - typically lower among the income poor but that they appear to be more satisfied than dissatisfied with their lives (see Rojas, 2004 on Mexico; Neff, 2009 on South India).

A second possible hypothesis is that income poverty is not associated with lower satisfaction levels. Here there are at least four possible explanations. First, income may not explain a great deal of subjective wellbeing. Satisfaction may be driven by latent personality traits (see Diener et al, 1999) or more closely associated with other domains of life. Recent evidence is somewhat supportive of both arguments. For instance, Diener and Lucas (1999) find that personality may explain up to 35 per cent of subjective wellbeing. When Helliwell et al (2012) explore the contribution of income to life satisfaction, using country level averages, they find that it explains some 65 per cent of variation. When they include other explanators relating to social support, freedom and corruption, however, they find the explanatory value of income falls by more than half. Second, poor people may derive satisfaction from other aspects of life that potentially offset the dissatisfaction occasioned by low incomes. A clear example is a study that compared slum dwellers, sex workers and pavement dwellers in Calcutta (Biswas-Diener and Diener, 2001). The study concluded that the three groups reported higher levels of satisfaction with their lives than might be expected and that the satisfaction they derived from their social relationships may have contributed to this overall satisfaction. Third, people may adapt to adverse circumstances to the extent that they do not depress their mental outlook. Amartya Sen has written extensively on what he terms 'valuation neglect' brought about by 'physical condition neglect'. Deprived people, he argues, may have 'learned to have "realistic" desires and to take pleasure in small mercies' (Sen, 1985: 14). Finally, some researchers argue that satisfaction may be, to varying extents, relative, particularly once basic needs are satisfied, and therefore conditioned by 'reference groups' perceived as important (see Merton, 1957; Luttmer, 2004; van Praag, 2011). This could affect perceptions in different ways, depending on whether the reference groups of the poor tend to be their peers, richer people or people defined by characteristics other than their income.

One way to probe the nature of the poverty-satisfaction relationship further is to explore the extent to which income may contribute, alongside other factors, to overall life satisfaction. Another is to consider whether and how people's perceptions change when they make a transition into and out of poverty. A large literature on poverty dynamics from many countries suggests that transitions in and out of poverty are frequent occurrences. For instance, in Chile, investigation of 1996-2001 panel data concluded that while 20 per cent of the population lived below the official poverty line in each year, only 9 per cent was poor at both points in time (Neilson et al, 2008).

Increasingly, it is evident that individual subjective assessments are not fixed solely by their current objective circumstances but by their expectations, aspirations, previous experiences and social reference groups' (Burchardt, 2005: 1). However, more research is needed to determine to what extent and how these factors matter. 
In this respect, the paper links to a growing body of research on the effect of income dynamics on subjective states (Brickman et al, 1978; Van Praag and Fritjers, 1999; Stutzer, 2004; Burchardt, 2005; Di Tella et al, 2007), which largely reports that people adapt to varying extents to shifts in their income.

This paper will contribute to this literature by exploring how (a) poverty status at a point in time and (b) transitions in and out of poverty contribute to life satisfaction. The analysis stands to provide a valuable perspective first in focusing on poverty and second, in considering a developing country setting, less studied owing to data constraints. ${ }^{4}$ On the one hand, absolute need is likely to be greater than in developed countries where much of this literature is focused, potentially amplifying a negative relationship between poverty and subjective wellbeing. On the other hand, the rapid fall in income poverty in recent years in Chile may have shifted reference norms, making poor people more sensitive to relative considerations - the effects of this may go in either direction.

This paper draws upon the work of the Oxford Poverty and Human Development Initiative (OPHI) on the 'Missing dimensions of poverty'. This initiative seeks to collect internationally comparable data on key aspects of wellbeing that arise in participatory and normative studies of poverty but for which data is not systematically collected in internationally-comparable survey instruments. The five dimensions are: quality of employment, agency and empowerment, shame and humiliation, violence and psychological wellbeing (see Oxford Development Studies, 2007). The resulting dataset allows an assessment of how income relates to multiple aspects of wellbeing both traditional dimensions typically included in standard household surveys but also key subjective dimensions. These data were collected for the first time in a nationally representative survey in Chile in 2009.

\section{Dataset and methodology}

The analysis draws on two rounds of data collection. It uses 2006 data from Chile's household survey (CASEN) and 2009 data collected by OPHI. The latter survey was conducted among a nationally-representative subsample of the 2006 sample, and repeated several of the 2006 CASEN modules alongside module's on OPHI's 'missing dimensions'.

The respondents in the 2006 and 2009 datasets can be identified as income poor or non-poor in each of these years, given that the full CASEN income module is available at both points in time. We have information available regarding satisfaction in different domains in 2009 only as these questions were not part of the original CASEN survey. The full sample is composed of 1,432 households and a total of 6,949 people. Of that total, 6,286 people were interviewed in 2006, 5,875 in 2009 and 5,212 people in both years.

This analysis hinges on per capita household income and income poverty status in 2006 and 2009, and satisfaction with life in 2009. Per capita income, in turn, is obtained adding up the incomes of all household members, from all possible sources, and dividing them by the household size in each period. ${ }^{5}$ As income cutoffs, we 
use the poverty lines used by MIDEPLAN for the official poverty estimates, which follow the Cost of Basic Needs Approach typically used in Latin American countries. The Total Poverty Line is computed as twice the cost of the Basic Food Basket in urban areas, and as 1.75 times the cost of the Basic Food Basket in rural areas. Table 1 presents the values of the poverty line in urban and rural areas in each year.

In the panel we observe 20.3 per cent of people as poor in 2006 and 34.4 per cent in 2009. While poverty has fallen markedly since the early 1990s, it increased in the 2006-9 period. The increase has been attributed to the 2008 global crisis rather than a reversal of trend.

What transitions have taken place? Table 2 presents the percentage of population in each category. In line with the increase in poverty observed in the panel from 2006 to 2009, we see that 22 per cent of the people in the panel were

Table I: Income poverty line

\begin{tabular}{|l|l|l|}
\hline Area & 2006 & 2009 \\
\hline Urban & 47,099 & 69,134 \\
\hline Rural & 31,756 & 43,242 \\
\hline
\end{tabular}

Notes: All values are in Chilean Pesos $(\mathrm{CH} \$)$. In July $2010 \mathrm{CH} \$ \mathrm{I}=\mathrm{US} \$$ 0.00188 . The PPP exchange rate of the Chilean Peso according to World Bank was 288.7.

Source: MIDEPLAN, http:// siteresources.worldbank.org/ ICPINT/Resources/Table5_7.pdf non-poor in 2006 but became poor in 2009, 8 per cent followed the reverse pattern and 12 per cent were poor in both years.

We construct a set of variables to account for poverty transitions. One denotes being poor in both years $(2006$ and 2009), another denotes being poor in 2006 but non-poor in 2009, a third accounts for those who were non-poor in 2006 but poor in 2009 and finally there is a variable for those who were non-poor in both years. ${ }^{6}$

Table 2: Income transitions in the panel

\begin{tabular}{|l|l|l|}
\hline $2006-09$ & Frequencies & $\%$ \\
\hline \multicolumn{2}{|l|}{ Into and out of poverty } \\
\hline Poor-poor & 638 & 12.24 \\
\hline Poor-non poor & 423 & 8.12 \\
\hline Non poor-poor & 1,165 & 22.35 \\
\hline Non poor-non poor & 2,986 & 57.29 \\
\hline Total & $\mathbf{5 , 2 1 2}$ & 100 \\
\hline
\end{tabular}

Source: own estimates using OPHI-CASEN panel survey

Life satisfaction is constructed on the basis of responses to the question 'In general, how satisfied or dissatisfied are you with your life overall?' to which respondents selected their level of satisfaction on a four-point scale ranging from 'very satisfied' (4) to 'not at all satisfied' (1). Mean life satisfaction in our sample is quite high, at 3.00, and only 24 per cent of respondents were dissatisfied with their lives in 2009 (they reported to be 'not very satisfied' or 'not at all satisfied'). Similarly structured questions were asked of respondents on their satisfaction with their income, food, housing, health, work, local security, friends, family, education, 'free choice and control' over their life, dignity, local area (neighbourhood, town, community), ability to help others, and finally spiritual, religious or philosophical beliefs. The mean score in each of these categories is depicted in Figure 1.

The questions on satisfaction were asked only to one respondent per household. Given a few cases of missing values we have a sample of between 1,345 respondents 
Figure I: Level of satisfaction in domains of life, 2009

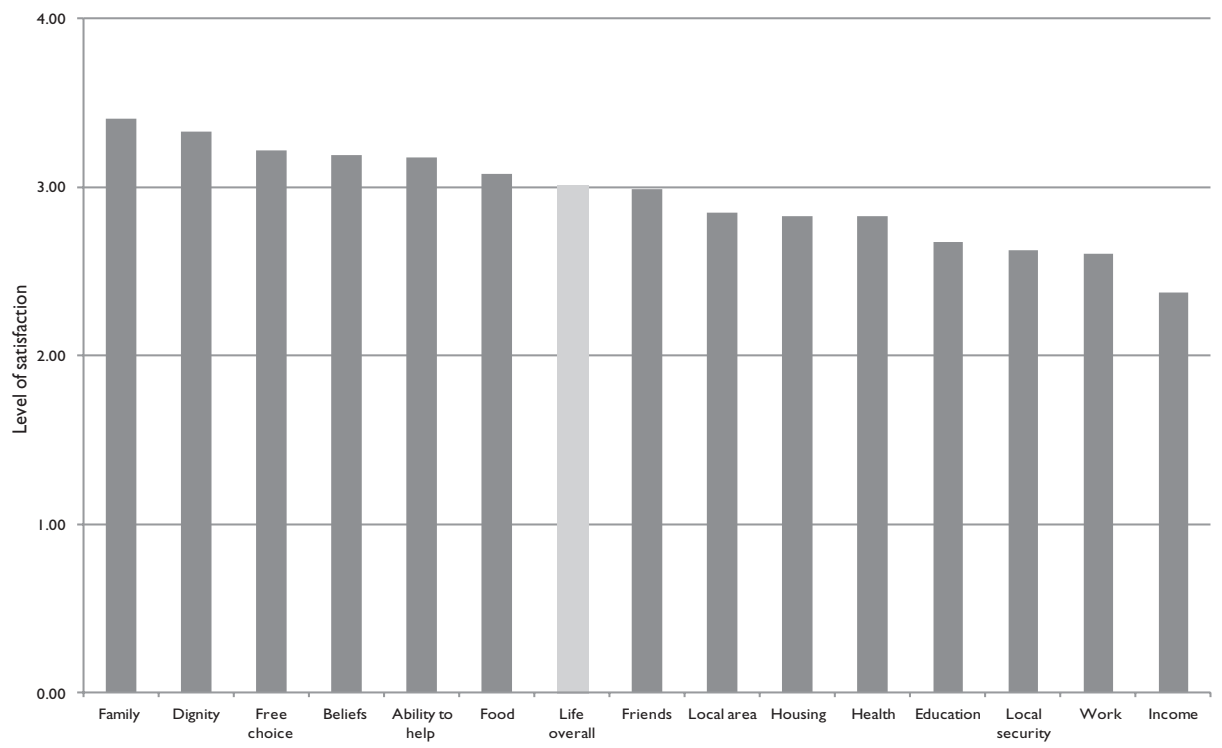

Source: Own estimates using OPHI-CASEN panel survey

(for the question on satisfaction with spiritual, religious or philosophical beliefs) and 1,429 respondents for the life satisfaction question.

Satisfaction with life has significant correlations with satisfaction in all the other domains. The (Spearman correlation) coefficients range from 0.32 (with local security) to 0.61 (with food), with most of the coefficients being between 0.40 and 0.51 . The correlation between life and income satisfaction is 0.47 .

To evaluate the linkages between income levels and transitions and subjective wellbeing, we use basic descriptive statistics and multivariate ordered probit regression analysis controlling for a set of factors that are known to influence subjective wellbeing.

\section{Links between income poverty, satisfaction with life and satisfaction with income}

\section{Poverty levels}

As a first approach, we compare satisfaction with life and across our range of domains for individuals in poor and non-poor households. We find that - on average - the poor are less satisfied than the non-poor, and all of the differences between the poor and non-poor groups are statistically significant (Table 3). The ranking of domains among both groups is fairly similar. Among both, satisfaction is highest with intangible aspects of life - family, dignity, free choice, beliefs and the ability to help 
Table 3: Mean satisfaction with life and its domains for poor and non-poor, 2009

\begin{tabular}{|l|c|c|c|c|}
\hline Domain & Poor & Non-poor & Total & Difference \\
\hline Family & 3.33 & 3.44 & 3.41 & 0.12 \\
\hline Dignity & 3.21 & 3.39 & 3.33 & 0.18 \\
\hline Free choice & 3.08 & 3.27 & 3.21 & 0.20 \\
\hline Beliefs & 3.12 & 3.22 & 3.19 & 0.11 \\
\hline Ability to help & 3.06 & 3.23 & 3.18 & 0.17 \\
\hline Food & 2.82 & 3.19 & 3.08 & 0.37 \\
\hline Life & 2.76 & 3.12 & 3.01 & 0.36 \\
\hline Friends & 2.86 & 3.04 & 2.99 & 0.18 \\
\hline Local area & 2.68 & 2.92 & 2.85 & 0.24 \\
\hline Housing & 2.58 & 2.94 & 2.83 & 0.36 \\
\hline Health & 2.65 & 2.91 & 2.83 & 0.26 \\
\hline Education & 2.48 & 2.76 & 2.67 & 0.29 \\
\hline Local security & 2.50 & 2.68 & 2.63 & 0.18 \\
\hline Work & 2.18 & 2.79 & 2.60 & 0.61 \\
\hline Income & 2.00 & 2.54 & 2.37 & 0.54 \\
\hline
\end{tabular}

Note:*All differences between poor and non-poor are significant at the $99 \%$ level.

Source: own estimates using OPHI-CASEN panel survey

others. For both groups, satisfaction with income is lower than for any other item. Interestingly, satisfaction with life falls exactly in the middle.

Figure 2 compares how poverty relates to responses to the four-point scale of the life satisfaction variable. Poverty status is associated with lower life satisfaction: a higher proportion of the poor are either 'not satisfied at all' or 'not very satisfied' compared to the proportion of the non-poor in these categories. Similarly, a lower proportion of the poor are in the 'satisfied' or 'very satisfied' categories when compared to the non-poor. Nonetheless, 62 per cent of the poor (and 82 per cent of the non-poor) are either satisfied or very satisfied with their lives.

We now explore the association of the poverty status on life satisfaction controlling for a number of characteristics, namely household location, demographic factors and employment status. ${ }^{7}$ As expected, belonging to a poor household is strongly and negatively associated with life satisfaction. The only controls that exert a significant effect on life satisfaction are being a male and being an employer, both with a positive association.

To understand how income conditions the satisfaction of the poor and non-poor individuals, we look at how income and satisfaction are related in our sample overall and in each of these groups. We find a positive, significant relationship between income and life satisfaction in our 2009 sample (with a correlation of 0.24). Surprisingly however, the correlation between income and life satisfaction among the poor is not significant, while the correlation among the non-poor only is low (0.15) but significant. We revisit this analysis regressing life satisfaction against (the 
Figure 2: Poverty condition and life satisfaction, 2009

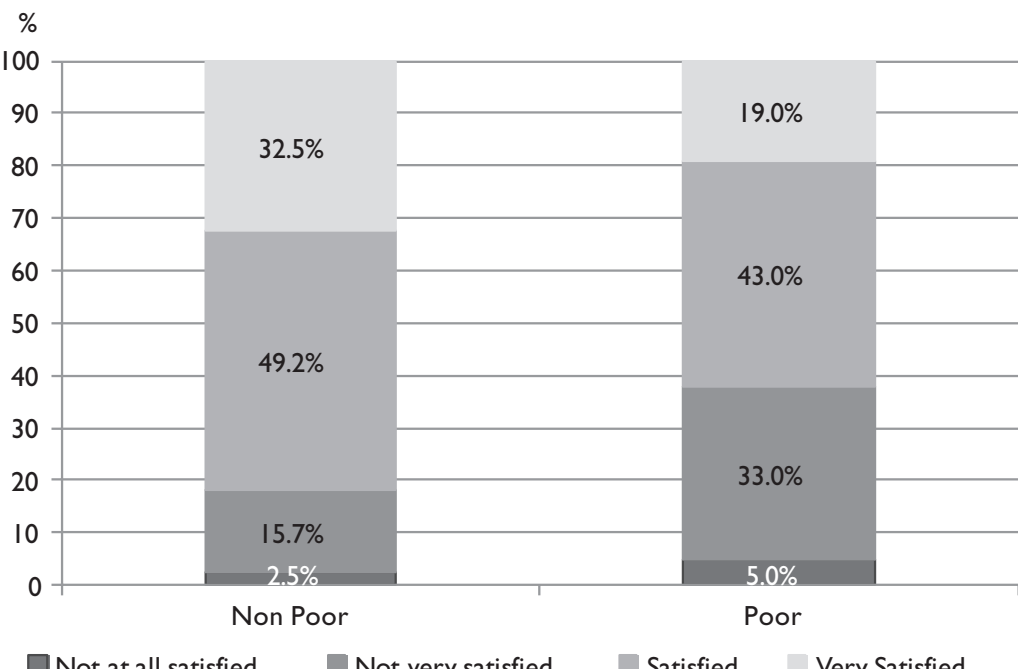

Not at all satisfied Not very satisfied Satisfied Very Satisfied

log of) income in 2009 (alongside the same controls as before) for the group of individuals who were poor in 2009 and for the group of those who were non-poor in 2009. ${ }^{8}$ This exercise enables us to predict the effects of a small income increase on life satisfaction among the poor and non-poor respectively (Table 4). Here too, we find that an income increase among the poor is not significantly associated with life satisfaction. On the other hand, an income increase among the non-poor is positively and significantly associated with greater life satisfaction. ${ }^{9}$

This result suggests that the link between income and life satisfaction may differ somewhat between the poor and the non-poor group, with income mattering more to the satisfaction of the non-poor. This result might be suggestive of a threshold effect at the lower end of the distribution such that below a certain (low) income

Table 4: Ordered probit model of life satisfaction with log income in 2009

\begin{tabular}{|l|c|c|}
\hline & \multicolumn{2}{|c|}{ Life Satisfaction } \\
\hline & Poor in 2009 & Non-poor in 2009 \\
\hline Log of Income 2009 & -0.017 & $0.291^{* * * *}$ \\
& $(-0.53)$ & $(5.23)$ \\
\hline Household location & $Y$ & $Y$ \\
Demographic factors & $Y$ & $Y$ \\
Employment status & $Y$ & Y \\
\hline Standardised coefficient & -0.0297 & 0.1992 \\
\hline Obs & 442 & 987 \\
\hline Chi2 & 39.16 & 51.33 \\
\hline
\end{tabular}

Notes: Absolute value of z-statistics in parentheses. ***: significant at the $1 \%$, **: significant at the $5 \%$, *: significant at the $10 \%$ level. 
level (such as the poverty line) under which the person is unable to satisfy her basic needs, a higher income may not increase life satisfaction significantly as the person cannot satisfy her basic needs anyway.

\section{Transitions in and out of poverty}

Having established that the poor are less satisfied than the non-poor with their lives and that income gains do not appreciably affect life satisfaction when individuals remain poor, we now consider the effect of income poverty transitions on satisfaction with life. Here, our model looks at the effects of transitions holding constant household location (urban vs rural), household size and the age, gender and the employment status (inactive, unemployed, employee or employer) of the respondent. Note that we

Table 5: Ordered probit model of life satisfaction with income poverty transitions 2006-09

\begin{tabular}{|l|c|}
\hline & Life satisfaction \\
\hline Poor-poor (base category) & \\
\hline Non poor-non poor & $\begin{array}{c}0.612^{* * *} \\
(5.79)\end{array}$ \\
\hline Non poor-poor & $\begin{array}{c}0.177 \\
(1.57)\end{array}$ \\
\hline Poor-non poor & $0.431 * *$ \\
& $(2.96)$ \\
\hline Household location & $Y$ \\
Demographic factors & $Y$ \\
Employment status & $Y$ \\
\hline Obs & $\mathrm{I}, 429$ \\
\hline Chi2 & 96.38 \\
\hline
\end{tabular}

Notes: Absolute value of z-statistics in parenthesis. ***: significant at the $1 \%$, **: significant at the $5 \%$, *: significant at the $10 \%$ level. The base category for employment status is being an employee. In the poverty transitions variables, the first category refers to the income category in 2006, and the second, to the income category in 2009. For example: poor-non poor means that the person was poor in 2006 but not in 2009.

do not intend to infer causality but rather to focus on associations.

In the set of variables for transitions, the base category is being poor both in 2006 and 2009, and the included categories correspond to those respondents that were non-poor at both points in time, poor in 2006 but non-poor in 2009 and vice versa. Table 5 presents our results, based on an ordered probit regression model. We see that being non-poor in both periods as well as having moved out of poverty between 2006 and 2009 are positively and significantly associated with life satisfaction. Also, being nonpoor in both periods is associated with greater life satisfaction than being nonpoor only in 2009. Interestingly, having moved into poverty between 2006 and 2009 has no significant association on life satisfaction, suggesting that recent poverty has a negative an effect on life satisfaction as does 'permanent' poverty. It would be interesting to see if this result holds if we considered poverty experienced for

longer than the three-year period for which we have data.

\section{Discussion and conclusions}

What does this analysis tell us about the relationship between poverty and subjective wellbeing? First, the life satisfaction of the sample on the whole is fairly high at 3.0 on a four-point scale. The poor display slightly lower satisfaction than the non-poor 
(2.76 versus 3.12) but the average satisfaction of the poor is still skewed towards being more satisfied with their lives rather than less so. Significantly, the poor are less satisfied than the societal average (and the non-poor) with all aspects of their lives than the non-poor (and all the differences are statistically significant), but the differences are greatest for incomes, work, education and local security, and less for intangible aspects such as family, dignity and free choice and control.

Second, being poor is significantly associated with having less satisfaction with life, after controlling for household location and key demographic factors, though we cannot say anything about the direction of causality (and indeed, it may run in both directions). In other words, being poor may be more likely to result in less satisfaction or those less satisfied may be more likely to be income poor.

Third, we looked at the predicted effect of income shifts among the poor and non-poor respectively. We found no significant association between income and life satisfaction among the poor (either unconditionally or holding explanatory variables constant) but it is positive and significant among the non-poor. This appears to contradict the idea that income matters more the less one has of it when one is below a poverty threshold. Rather, it seems that when people remain unable to meet their basic needs, more or less income does not significantly change their satisfaction with life.

Finally, transitions into and out of poverty appear to affect people's subjective states as well, even over a relatively short period. In particular, those people who were not poor in 2006 nor in 2009 had higher life satisfaction than people who were poor in both of those periods. Those who fell into poverty were no more satisfied with their lives than those who were poor in both periods. Those who climbed out of poverty between 2006 and 2009 exhibited a markedly increased satisfaction with their lives. In other words, changes in poverty status would appear to have fluid and significant associations with life satisfaction, with recent impoverishment being perceived 'as bad as' the experience of permanent poverty. The evidence would appear consistent with a lack of subjective adaptation by the poor.

This finding would seem to be inconsistent with the literature on adaptation, in so much as it applies to the income poor, as the poor in our sample not only seem less satisfied with their lives than their richer counterparts but movements out of poverty are associated with a significant increase in life satisfaction. This stands in contrast to most literature focusing on the relationship between changes in income and life satisfaction, which focuses on the whole of the income distribution and which generally finds evidence of some sort of adaptation to income shifts. Equally, in light of the drastic fall in poverty that Chile has experienced in recent years, where a large share of the population has escaped poverty in a short period of time, it might be that as reference norms have shifted, so have expectations - and that transitions out of poverty raise satisfaction as people achieve what they expect (and what many peers have accomplished) while those who remain poor (or fall into poverty) become frustrated with their standing. More research is needed along these lines.

The analysis of course has limitations. Our measure of life satisfaction - with its four-item response structure - may not be sufficiently finely nuanced to pick up 
more subtle changes in how people feel about their lives. Despite having available panel data which traces changes in income over time to satisfaction levels for individuals, there remains a question of causation - namely, do changes in income prompt changes in people's psychological states, or do changes in psychological states bring about changes in income, or are the two mutually reinforcing? Moreover, we are unable to explore the effects of longer poverty spells - it could be that people who are chronically poor over a longer period differ in some systematic way from those who were able to escape poverty in the period under study. The literature on adaptation assumes that subjective states alter in response to income but more evidence on how this happens would be useful. Finally, we need to go beyond knowing that income is linked to satisfaction to knowing why it is linked and what particular factors mediate the linkage.

Nonetheless, this study seeks to contribute to a growing body of knowledge about how income and income poverty shape people's feelings about their lives. It is generally acknowledged that income is inadequate as a measure of welfare, but that satisfaction measures too require greater scrutiny, not least to understand the extent to which they reflect objective circumstances and can be usefully compared among people. As interest in subjective measures grows, alongside a growing impetus to use this knowledge in policy domains, more information is needed about how people judge how satisfied they are with their lives, and whether and how these measures have policy legitimacy and relevance.

\begin{abstract}
Notes
${ }^{1}$ According to Economic Commission for Latin America and the Caribbean (ECLAC) estimates using the Encuesta de Caracterización Socioeconómica Nacional (CASEN) dataset, poverty fell from 38.6 per cent in 1990 to 13.7 per cent in 2006 and indigence, from 13 per cent to 3.2 per cent (Alicia Barsena, Introductory speech to the International Conference on 'Multidimensional poverty measurement in Latin America', Santiago de Chile, 13-14 May 2010).

2 The two measures are often used interchangeably though psychologists assert that happiness measures affect and satisfaction, cognition or judgement. The survey on which this paper is based measured both satisfaction and happiness, though here we confine our analysis to the former.
\end{abstract}

${ }^{3}$ The difference seems to hinge in large part on whether the relationship between income and satisfaction is considered to be log-linear.

${ }^{4}$ Though presently an OECD member, Chile is still currently defined as a developing country according to World Bank classifications. Its per capita income of US $\$ 12,280$ falls just below the threshold of US $\$ 12,475$, placing it in the 'upper middle income' category.

5 We use the per capita household income rather than the equivalent income in line with the methodology followed by the Ministerio de Planificación y Cooperación de 
Chile (MIDEPLAN) for its official income poverty estimates. The CASEN has a very detailed income questionnaire, which enquires about labour incomes from primary and secondary occupation as well as from casual work, income from rent of property and physical capital, utilities, dividends, interest from deposits, remittances, donations, and all government transfers, including pensions, subsidies and family allowances. Additionally, it requests that the interviewed person estimates the quantity of income received in kind forms and production for self-consumption. We consider all income sources for the household's income indicator.

${ }^{6}$ These are $0 / 1$ 'dummy' variables. We also tried a different specification of the transitions considering a broader set of categories using not only the poverty line but also the indigence line (which corresponds to the cost of the basic food basket). However, when using this further discrimination between groups, the transitions had the expected signs but were largely insignificant - which seems to be an effect of the small number of people within each transition group. For this reason, we focus the discussion on transitions above and beyond the poverty line.

${ }^{7}$ Ordered probit and logit regressions with life satisfaction as the dependent variable. Estimations are available from the authors upon request.

${ }^{8}$ An alternative way to perform this analysis was to estimate a unique overall regression (considering the poor and non-poor) and then analyse the probability change in each of the possible levels of life satisfaction for the poor and the non-poor. We found this type of analysis to be less clear than the one presented here, although overall consistent.

${ }^{9}$ The standardised coefficient indicates that for a standard deviation increase in the (log of) income among the non-poor, life satisfaction is expected to increase in 0.20 standard deviations, holding all other variables constant. We used the command listcoef, std help in Stata, designed by Long and Freese (2001).

\section{References}

Biswas-Diener, R. and Diener, E. (2001) 'Making the best of a bad situation: satisfaction in the slums of Calcutta', Social Indicators Research, 55(3):329-52, http:// positiveacorn.com/wp-content/uploads/2012/01/Biswas-Diener_2001.pdf.

Brickman, P. and Campbell, D.T. (1971) 'Hedonic relativism and planning the good society', in M.H. Appley (ed) Adaptation level theory: A symposium, New York: Academic Press, pp 287-302.

Brickman, P., Coates, D. and Janoff-Bulman, R. (1978) 'Lottery winners and accident victims: is happiness relative?', Journal of Personality and Social Psychology, 36(8): 917-27.

Burchardt, T. (2005) 'Are one man's rags another man's riches? Identifying adaptive expectations using panel data', Social Indicators Research, (74): 57102. 
Comision Economica para America Latina y el Caribe (CEPAL) (2000) 'Equidad, Desarrollo y Ciudadania', Santiago:CEPAL, www.eclac.cl/publicaciones/xml/5/4425/ $\operatorname{lcg} 2071$.pdf.

Deaton, A. (2008) 'Income, health and wellbeing around the world: evidence from the Gallup World Poll', Journal of Economic Perspectives, 22(2): 53-72.

Di Tella, R., Haisken-De New, J. and MacCullough, R. (2007) 'Happiness adaptation to income and status in an individual panel', Working Paper 13159, Cambridge: National Bureau of Economic Research (NBER).

Diener, E. and Lucas, R.E. (1999) 'Personality and subjective wellbeing', in D. Kahneman, E. Diener and N. Schwarz (eds) Wellbeing: The foundations of hedonic psychology, New York: Sage Foundation, pp 213-29.

Diener, E., Suh, E.M., Lucas, R.E. and Smith, H.L. (1999) 'Subjective wellbeing: three decades of progress', Psychological Bulletin, 125: 276-302.

Easterlin, R. A. (1974) 'Does economic growth improve the human lot? Some empirical evidence', in P.A. David and W.R. Melvin (eds) Nations and Households in Economic Growth, Palo Alto, CA: Stanford University Press, pp 98-125.

Helliwell, J., Layard, R. and Sacks, J. (2012) World Happiness Report, New York: The Earth Institute, Colombia University, www.earth.columbia.edu/sitefiles/file/ Sachs\%20Writing/2012/World\%20Happiness\%20Report.pdf.

Larrañaga, O. (2009) 'Inequality, poverty and social policy: recent trends in Chile', OECD Social Employment and Migration Working Paper 85, Paris: OECD.

Long, J.S. and Freese, J. (2001) Regression models for categorical dependent variables using Stata, College Station, TX: StataCorp.

Luttmer, E. (2004) 'Neighbors as negatives: relative earnings and well-being', Quarterly Journal of Economics, 120(3): 963-1002.

Merton, Robert K. (1957) Social Theory and Social Structure, Glencoe, IL: Free Press of Glencoe.

Neff, D. (2009), 'The satisfied poor: evidence from South India,' Brooks World Poverty Institute (BWPI) Working Paper 7109, Manchester: The University of Manchester, BWPI.

Neilson, C., Contreras, D. and Hermann, J. (2008) 'The dynamics of poverty in Chile', Journal of Latin American Studies, 40(2): 251-73.

Oxford Development Studies (2007) 'The missing dimensions of poverty data' (Special Issue), Oxford Development Studies,35(4).

Rojas, M. (2004) 'Wellbeing and the complexity of poverty: a subjective wellbeing approach' UNU-WIDER Research Paper RP2004/29. Helsinki: UN-WIDER.

Sen, A. (1985) Commodities and Capabilities, Amsterdam: North-Holland.

Stevenson, B. and Wolfers, J. (2008) 'Economic growth and subjective well-being: reassessing the Easterlin Paradox,' Working Paper, Philadelphia, PA: Wharton School, University of Pennsylvania, prepared for Brookings Papers on Economic Activity, Spring.

Stutzer, A. (2004) 'The role of income aspirations in individual happiness', Journal of Economic Behavior and Organisation, 54(1): 89-109. 
Van Praag, B. (2011) 'Well-being inequality and reference groups: an agenda for new research,' Journal of Economic Inequality, 9(1): 111-27.

Van Praag, B.M.S. and Fritjers, P. (1999) 'The measurement of welfare and wellbeing: the Leyden approach', in D. Kahneman, E. Diener and N. Schwarz (eds) Well-being: Foundations of hedonic psychology, New York: Russell Sage Foundation Press.

\section{Emma Samman \\ Overseas Development Institute, London, UK \\ e.samman@odi.org.uk}

\section{María Emma Santos}

Instituto de Investigaciones Económicas y Sociales del Sur (IIES),

Departamento de Economía UNS (CONICET), Argentina, and

Oxford Poverty and Human Development Initiative, UK

maria.santos@qeh.ox.ac.uk 